CARDIAC CARE

\title{
Modification of self-concept in patients with a left-ventricular assist device: an initial exploration
}

\author{
Linda Marcuccilli, Jesus Casida and Rosalind M Peters
}

\begin{abstract}
Aims and objectives. To explore how patients with left-ventricular assist devices (LVAD) meet the health-deviation requisite of modifying self-concept to accept this form of treatment and restore normalcy.

Background. LVAD are becoming a standard option to improve the quality of life for patients with advanced heart failure. Past research focused on technology issues and survival rates, but limited research has addressed the effect of LVADs on patients' perceptions of self. Orem's theory of self-care provides a framework to investigate how patients manage threats to self-concept to safely live with such a device.

Design. Hermeneutic phenomenology based on van Manen's method.

Method. Data were collected using semi-structured interviews. Data saturation was achieved with nine participants (seven men; two women), 31-70 years of age who lived with a LVAD at home for at least three months. Thematic analysis was ongoing, and final themes were consensually validated.

Results. Two themes constructed from the data were consistent with the requisite of modifying self-concept. First, Having a LVAD means living. Participants described they 'feel alive again', and they 'had the rest of [their] lives that they didn't have before'. The second theme: A desire to be 'normal' in public, arose from participants descriptions of how the LVAD brought unwanted attention to them and that their appearance was 'shocking' to others.

Conclusion. Participants accepted the LVAD as necessary to live making it easier for them to modify their self-concept and accept the changes to their bodies and daily lives. Attaining a sense of normalcy was more difficult in public and required additional lifestyle modifications.

Relevance to clinical practice. Findings advance self-care knowledge in LVAD management and can heighten nurses' awareness about self-concept as a vital component for maintenance of health and well-being.
\end{abstract}

Key words: cardiovascular, phenomenological hermeneutics, self-care, self-concept

Accepted for publication: 24 June 2012

\section{Introduction}

There are almost 6 million Americans diagnosed with heart failure $(\mathrm{HF})$ in the United States (American Heart Association 2010). Owing to the chronic and progressive nature of HF, more than 100,000 patients with advanced/end-stage heart failure will experience progressive symptoms (e.g. marked shortness of breath) unresponsive to maximum medical management (American Heart Association 2010). Because of the limited availability of donor organs and increasing prevalence of HF risk factors (e.g. hypertension, etc.), mechanical circulatory support with a left-ventricular
Authors: Linda Marcuccilli, PhD, RN, Post-Doctoral Fellow, Research Scientist, Training in Behavioral Nursing Research, Indiana University Purdue, Indianapolis, IN; Jesus Casida, PhD, RN, APN-C, CCRN-CSC, Assistant Professor, Division of Acute, Critical, and Long-term Care, Robert Wood Johnson Foundation Nurse Faculty Scholar Alumnus, The University of Michigan School of Nursing, Ann Arbor, MI; Rosalind M Peters, PhD, RN,
FAAN, Associate Professor, College of Nursing, Wayne State University, Detroit, MI, USA

Correspondence: Linda Marcuccilli, Post-Doctoral Fellow, Research Scientist, Training in Behavioral Nursing Research, Indiana University Purdue, 1111 Middle Drive, NU 345D, Indianapolis, IN 46202-5107, USA. Telephone: +1 3135731552.

E-mail:1marcucc@iupui.edu; lckmster@hotmail.com 


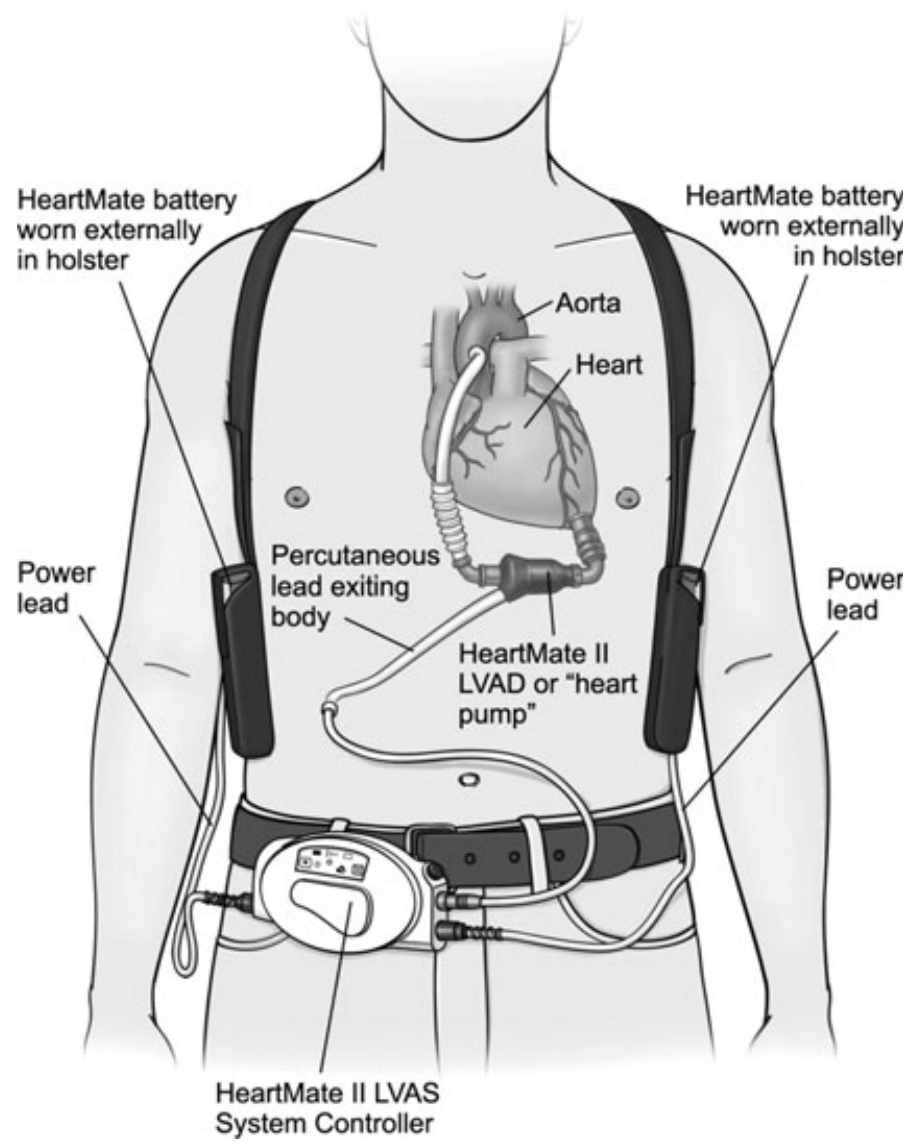

Figure 1 External components of left-ventricular assist device. Reprinted with permission from Thoratec Corporation, 2012.

assist device (LVAD; Fig. 1) is becoming a therapy of choice for patients with advanced HF. An LVAD can be used for patients waiting for a transplant [i.e. bridge-to-transplant (BTT)], or as a permanent alternative to transplant [i.e. destination therapy (DT)] (Hunt et al. 2005). In either situation, LVADs have been shown to sustain life and improve patient's quality of life (QoL) (Grady et al. 2001, 2002, 2003, 2004).

Although LVADs have improved the QoL of advanced HF patients, living with this implanted device may cause major psychosocial issues for patients. For example, patients with LVADs are attached to internal and external components (Fig. 1) which can cause psychological distress and potentially alter perceptions of self-concept (e.g. mental images about the self in relation to the body). Thus, patients may have difficulty in modifying self-concept which can affect their ability to carry out the required self-care of the LVAD system, affect ego integrity and also affect their willingness to engage in social relationships. The ability to modify self-concept, therefore, is vital for promoting and maintaining emotional integrity, continued adherence to LVAD regimen, and the development and continuation of social relationships leading to improved QoL.
Although a few studies have identified threats to self-concept (Chapman et al. 2007, Casida et al. 2011), to date, no published studies were found that investigated how patients with LVADs modify their self-concept. The current study seeks to address this gap in knowledge and uses the theory of self-care (Orem 2001) as a framework to guide this study.

\section{Theoretical framework}

Within the theory of self-care (Orem 2001), patients are viewed as self-care agents capable of making conscious choices regarding the self-care to be performed. Self-care refers to the actions people take to meet self-care requisites required to maintain structural and functional integrity. The person's ability to perform the needed self-care actions is referred to as self-care agency. A self-care deficit is said to exist when the person's agency is not sufficient to meet known self-care requisites. There are three types of requisites that persons must meet for optimum health: universal, developmental and health-deviation. Universal requisites must be met by all persons at all stages of the life cycle and are 
necessary for maintaining human structure and functioning. Developmental requisites are concerned with conditions needed for development, engagement in self-development, and prevention or overcoming threats to human development (Orem 2001, p. 231). Health-deviation requisites (HDSCR) are additional requirements that must be met due to pathology and/or medical diagnostic or treatment procedures. Orem addressed the importance of self-concept in meeting one's self-care demands in the following HDSCR: Modifying the self-concept (and self-image) in accepting oneself as being in a particular state of health and in need of specific forms of health care (Orem 2001, p. 235).

In this study, we focused on the reformulated, LVAD-specific HDSCR that relates to self-concept which is:

1 Modify self-concept by accepting oneself as being in need of technology-assisted living to attain self-acceptance sufficient for continuous engagement in therapeutic LVAD self-care.

2 Modify self-image to preserve ego integrity and psychosocial-sexual relationships while living with an LVAD (Casida et al. 2009, p. 287).

Modifying self-concept, therefore, is necessary for patients to carry out the self-management aspects of LVAD care, as well as necessary for achieving psychological and social well-being, all of which contribute to their overall QoL.

Although limited literature suggested that patients with LVADs may have difficulty modifying their self-concept and may not attain the level of acceptance necessary to follow the prescribed LVAD care regimen (Chapman et al. 2007, Casida et al. 2009, 2011), we do not know how patients with LVADs perceive and/or modify their selfconcept and self-image related to living with an implantable LVAD. Because of the absence of data on 'self-concept' in the LVAD literature, the study aimed to uncover the phenomenon drawn from the lived experiences of the recipients. Thus, the purpose of this study was to explore how patients with LVADs meet the health-deviation requisite of modifying self-concept and self-image to accept this form of treatment and determining what they need to do to restore normalcy.

\section{Methods}

A hermeneutic (e.g. interpretive) phenomenological study based on the methods of van Manen (1990) was used to explore and understand self-concept among patients with LVADs. This method consists of both empirical and reflective activities to elicit the meaning of the lived expe- rience. The empirical activities are conducted to obtain lived experience sources (e.g. demographic profiles, participant interviews and field notes), and the reflective activities are performed to interpret the meaning behind the phenomenon of concern. The in-depth meanings of a phenomenon are accessed through the collective language, or narratives, of persons who have experienced the phenomenon from a first-person perspective (van Manen 1990). The researcher interprets participants words 'fixed as text' and describes the essence or meaning of the lived experience through the language of writing (e.g. semiotics) (van Manen 1990).

\section{Participants and setting}

Recruitment took place in an outpatient mechanical circulatory support (MCS) programme of a University Medical Centre located in the Midwest. Participants were eligible for the study if they were English-speaking men and women, 21 years old and over, lived with an LVAD three or more months at home and had no evidence of cognitive decline. Exclusion criteria included unable to read, write, or speak English, $<21$ years of age, exhibited evidence of cognitive decline and had an LVAD for less than three months. A purposive convenience sample of nine men and women were approached and volunteered for the study. Recruitment stopped after responses with nine participants became redundant. In accordance with standards for qualitative research (Lincoln \& Guba 1985), sampling was stopped when no new information emerged from the interviews, thus redundancy (i.e. saturation) was the primary criterion used to determine sample size.

\section{Ethical considerations}

Prior to recruitment and data collection, a letter of support was obtained by the supervisor for the MCS programme and approved by the university Human Investigation Committee. Consent was reviewed in a private setting, and sufficient time was allowed for questions and answers. Participants were informed that all information is held in strict confidence with no identifiable markers on any data. Although the risks associated with the study were minimal (i.e. fatigue and/or anxiety), consultation services with a member of the psychosocial team was available upon request. Informed consent was obtained after study purpose, risks, and roles were understood by participants.

There are six steps in van Manen's (1990) method which were used to guide this study: (1) Turning to the phenomenon; 
(2) Exploring the lived experience; (3) Reflecting on essential themes characterising the experience; (4) Phenomenological writing; (5) Remain focused and oriented; and (6) Balancing the inquiry through parts and wholes (van Manen 1990).

\section{Data collection}

Data collection began with the first research activity, turning to the phenomenon (van Manen 1990), by formulating the phenomenological question and using bracketing procedures. Bracketing, or suspending biases or preconceived knowledge, is a technique described by van Manen (1990) to enhance research objectivity throughout the study. Two bracketing strategies were used in this study. First, the primary investigator (PI) maintained a reflective journal to openly disclosed personal perceptions, assumptions and biases about living with an LVAD. Second, the PI engaged in ongoing discussions with other members of the research team in order to remain open to participant voices and meaning of the phenomenon.

The second research activity commenced with the strategies for exploring the lived experience (van Manen 1990). This step entails accessing the setting, obtaining a sample and collecting lived experience sources from participants' best suited to give voice to the phenomenon of concern. Using a questionnaire as a guide, semi-structured, in-depth interviews were conducted and tape-recorded with seven men and two women, 31-70 years old in a private conference room located in the outpatient MCS centre. The average implant duration of LVAD support as destination therapy was 1.5 years $(S D \pm 1.4 ; \quad$ range $=6$ months -4 years) (Table 1). Participant interviews commenced with the following questions: 'Tell me how living with the LVAD has affected your perception of your self-concept, self-image and what strategies helped you accept this new image?' Probing questions such as 'What do you mean by...Can you tell me more about...' were used to elicit thick descriptions of the data. van Manen (1990) described probing questions as the gateway for discovery of the meaning of the phenomenon as participants' experience, because meanings are accompanied by reflecting and refocusing on the phenomenon. During and after each participant interviews, the PI composed field notes, which made note of the usage of particular words, phrases and the association of verbal and non-verbal body language. van Manen (1990) described field notes, as the experiential anecdote, necessary for describing areas needing further exploration in subsequent interviews. Interviews lasted 15-102 minutes. Participant interviews were transcribed by a trained transcriptionist and verified by the PI for accuracy.

The third research activity involved reflecting on essential themes characterising the experience to understand the meaning about the phenomenon under study (van Manen 1990). The PI downloaded all lived experience sources into the NVIVO, version 8 (QSR International, Cambridge, MA, USA) qualitative software to assist in the organisation and identification of emerging themes. Recorded interviews were listened to several times, and transcribed texts were verified for accuracy. All transcriptions and field notes were read and reread several times prior to engaging in further interviews. van Manen (1990) calls this process immersion, which requires engaging with the meaning of the texts to gain insight into preliminary or emerging themes. Data collection stopped after responses with nine participants became redundant. In accordance with standards for qualitative research (Lincoln \& Guba 1985), sampling was stopped when no new information emerged from the interviews, thus redundancy (i.e. saturation) was the primary criterion used to determine sample size.

Table 1 Participants socio-demographic and clinical data

\begin{tabular}{|c|c|c|c|c|c|c|c|c|}
\hline Participant & $\begin{array}{l}\text { Age } \\
\text { (years) }\end{array}$ & Sex & Race & $\begin{array}{l}\text { Education } \\
\text { (years) }\end{array}$ & $\begin{array}{l}\text { Marital } \\
\text { status }\end{array}$ & $\begin{array}{l}\text { Designated } \\
\text { caregiver }\end{array}$ & $\begin{array}{l}\text { Reason for } \\
\text { LVAD }\end{array}$ & $\begin{array}{l}\text { Years with } \\
\text { LVAD }\end{array}$ \\
\hline 1 & 50 & Male & Black & 12 & Married & Spouse & BTT & 0.5 \\
\hline 2 & 66 & Male & White & 14 & Widowed & Son & DT & $3 \cdot 5$ \\
\hline 3 & 31 & Male & Black & 12 & Single & Sister & BTT & $4 \cdot 0$ \\
\hline 4 & 56 & Male & White & 12 & Divorced & Family & DT & $1 \cdot 0$ \\
\hline 5 & 60 & Male & White & 13 & Married & Spouse & BTT & 0.5 \\
\hline 6 & 70 & Male & White & 18 & Married & Spouse & BTT & 0.5 \\
\hline 7 & 70 & Female & White & 16 & Married & Family & BTT & 0.5 \\
\hline 8 & 52 & Female & Defer & 12 & Divorced & Family & BTT & $2 \cdot 5$ \\
\hline 9 & 46 & Male & White & 12 & Married & Self & BTT & 0.5 \\
\hline
\end{tabular}

BTT, bridge-to-transplant; DT, destination therapy. 


\section{Trustworthiness}

To determine methodological rigour and enhance objectivity, steps to determine trustworthiness were incorporated throughout the study and included: (1) credibility, (2) transferability; (3) dependability and (4) confirmability (Lincoln \& Guba 1985).

Credibility is the determination that the findings are reliable (Lincoln \& Guba 1985). Prolonged engagement, peer debriefing and member checks were used to ensure credibility. Prolonged engagement was demonstrated by a thorough documentation of participant interviews, including length of immersion with data. Peer debriefing involved a review of overarching themes by an independent investigator, which were then consensually validated. Member check consisted of a telephone call performed by the PI after final themes were constructed to confirm interpretation of themes. According to Lincoln and Guba (1985), member check is the most important procedure for determining credibility.

Transferability is the extent to which the findings of the study may apply to other contexts or settings (Lincoln \& Guba 1985). We have facilitated transferability by using a purposive sample, providing details regarding our research context, and presenting thick descriptions of our procedures, findings and underlying assumptions. Determining transferability is the responsibility of the person interested in making a transfer (Lincoln \& Guba 1985).

Dependability assesses the quality of the methodological procedures (Lincoln \& Guba 1985). Confirmability measures how well the results are supported by the data collected and could be confirmed or corroborated by others (Lincoln \& Guba 1985). To address dependability and confirmability, an audit trail was maintained by the PI and an inquiry audit was performed by a member of the research team with qualitative expertise. Validation of research findings was confirmed by a thorough examination of the research process, methods, procedures, findings and implications. The audit inquiry concluded that the research findings and conclusions were supported by the data.

\section{Data analysis}

Phenomenologic analysis was performed to interpret the essence, or meaning of the lived experience from insiders' perspectives (van Manen 1990). The researchers used the wholistic, selective (e.g. highlighting) and detailed (e.g. lineby-line) approach described by van Manen (1990) to guide thematic analysis. The wholistic approach involved reading the transcribed texts as a whole, and the selective and detailed approach focused on the parts, or sections, of the transcribed texts. First, transcribed texts were reviewed as a whole to find the overall meaning of the text (wholistic). Next, each sentence and/or phrase was reflected upon to see which phrases or words may represent the phenomenon (selective). While reading and reflecting on participant texts, phrases and/or worlds that uncovered the meaning of the study phenomenon were chosen (detailed). The researchers engaged in constant comparison of these words and phrases and all lived experience sources to search for participants' shared meanings and differences related to the study phenomenon (van Manen 1990).

The fourth research activity involved phenomenological writing (van Manen 1990). In this activity, thematic phrases were constructed through analytical reflection of the lived experience sources, including writing and rewriting, and reflecting to capture the essence of the lived experience. Emerging themes were organised and coded into words and phrases using the qualitative software Nvivo, version 8 (QSR International). The culmination of these three approaches produced clustered topics which were reduced into two main themes that illustrated the essence of modifying self-concept and self-image while living with the LVAD. Final themes were consensually validated by all members of the research. van Manen (1990) concluded that the themes constructed through this process illustrates the meanings ascribed to the human experience.

The fifth research activity, remain focused and oriented (van Manen 1990), called for the researcher to have a focused orientation towards the phenomenon of interest, the research questions and the phenomenological inquiry. The researchers remained focused on the research questions and methods through interviews with participants and maintained close observation. This was achieved by remaining open to the participants words, listening to descriptions of the experience as lived and formulating probing questions as conversations unfolded.

The final activity focused on balancing the inquiry through parts and wholes (van Manen 1990). In this activity, researchers compared the whole of the study against the lived experience sources, in the development of the final phenomenological narrative. This circular movement from the parts to the whole, stepping back and reflecting on interpretations, constitutes the hermeneutic circle. Through reflection and analysis, this process allowed the researchers to explore the lived experience sources at deeper levels in order to interpret the essence of how participants modified self-concept and self-image to restore normalcy while living with the LVAD. 
Table 2 Themes illustrating self-concept among patients with left-ventricular assist devices

\begin{tabular}{|c|c|}
\hline Themes & Excerpts from participants \\
\hline $\begin{array}{l}\text { Having an LVAD } \\
\text { means living }\end{array}$ & $\begin{array}{l}\text { I just looked [at the LVAD] and I think, "I've got to do this the rest of my life." I realize I have the rest of my } \\
\text { life to live now, and I didn't before. I thought I would really feel strange and want to avoid looking at myself } \\
\text { in mirrors, but I realize it saved my life. You know? I'm alive to look in the mirror } \\
\text { It [the LVAD] doesn't bother me. I mean, to be honest with you, I walk around, I don't go, like, see a person } \\
\text { staring at me because... But, self-image-wise, I feel normal. I mean, in my normalcy. I mean, I feel no different. } \\
\text { Actually, I mean I'm better physically. And mentally, I'm okay... } \\
\text { I guessed I realized...I'm human...I'm not gonna always be able to do...everything that I used to...it's like... } \\
\text { realizing your not } 20 \text { anymore you know...just simple things...of course at this point in my life I mean I... } \\
\text { I know I can't do everything that I used to so this is not a big inconvenience...for my lifestyle }\end{array}$ \\
\hline $\begin{array}{l}\text { A desire for normalcy } \\
\text { in public }\end{array}$ & $\begin{array}{l}\text { I sometimes will wear a different type of jacket so I don't upset people too much, you know, 'cause it [LVAD] } \\
\text {...you know... [people] get shocked when they see someone with wires stickin out all over [them]... } \\
\text { [I was] walking into a bank you know...you see everyone's eyes are on you (laughing) and I even had a couple } \\
\text { of guards come up to me... and grab me by the arm.... [it makes me feel like] your in a fishbowl (laughing)... } \\
\text { but again....i've gotten used to it" (being stared at in public) } \\
\ldots \text { people on the outside, though...if you're here (MCS)...uh no problem cause a lot of people have a LVAD } \\
\text { machinery but if you're out in public... and they see this [LVAD]...they'll look at it... and if you catch em } \\
\text { lookin at it... (participant looking up and away)... they will look another way...like there is something that's } \\
\text { wrong...you know...uh...they're not open to say well what the hell is that (strangers)...you know... but uh... } \\
\text { but that's all I see out there...not much else... } \\
\text { Sometimes people turn and stare a little bit and then just look away. I have never... I'm surprised. I have never } \\
\text { had anyone stop me and say, "What are you wearing?” which kind of surprised me. I never have had that. } \\
\text { Sometimes if I'm, I'm standing in line at a checkout counter at the grocery store, or Wal-Mart, or someplace, } \\
\text { I'll get into a conversation with the sales clerk and I can see that they're kind of wanting to ask but just don't } \\
\text { know how, and I just politely say, "I have a heart pump.” Now of course friends, people that know me, the } \\
\text { minute they saw me wanted to know all about it. But strangers, I have never had a stranger ask me what I'm } \\
\text { wearing }\end{array}$ \\
\hline
\end{tabular}

LVAD, left-ventricular assist devices.

\section{Results}

Two main themes were interpreted from the transcribed texts: (1) Having the LVAD means living; and (2) A desire to be normal in public (Table 2). Participant responses in Table 1 are a compilation of some of the rich descriptions used to interpret the experience and meaning of selfconcept and self-care actions used to accept the new image of living with an LVAD from insiders' perspectives.

\section{Theme 1: Having the LVAD means living}

As participants reflected upon their new lives with the LVAD, it appeared that they accepted their new selfconcept as living with this life-sustaining device. Responses such as 'didn't affect self-image' and 'life is living with the LVAD' were reported unanimously across all participants (Table 2). A female participant richly described perception of her new self-concept with the LVAD:

I just looked [at the LVAD] and I think, I've got to do this the rest of my life'. I realize I have the rest of my life to live now, and I didn't before. I thought I would really feel strange and want to avoid looking at myself in mirrors, but I realize it saved my life. You know? I'm alive to look in the mirror.

As participants reflected on their new lives with the LVAD as making them 'feel alive again', they described how they continued to participate in activities of daily living (ADLs), including engaging in personal and social relationships. This included visiting with friends, performing ADL, such as caring for the LVAD system, grocery shopping and engaging in social activities. Being able to perform ADLs and to continue to foster personal and social relationships was vital to their self-image, which was consistent with a modified self-concept. Within this context, they described for us that they 'could almost do anything' with the LVAD, although getting used to living with the LVAD was 'frustrating' at times. Yet, they accepted their new way of living, as described by one male participant:

[I can] almost do anything that I wanna do...somethings I can't... get little bit frustrating...but it's like wearing glasses...sometimes it's frustrating...but...by golly they work, an' that's just the way it 
is so you make the most of whatch you've got....I don't feel...like I say... any abnormality with it...

It appeared that the majority of participants readily modified their self-concept and accepted that they needed this life-sustaining device. They felt it was easy to adjust to their new life with the LVAD. Comments such as 'easy to get used to, not as bad as I thought it was going to be,' echoed throughout participants' texts, and richly detailed by a male participant: '...once I had it on an'...you know, you kind of experiment with it so...so yeah I can do this or... I can do that....an'...it's not... as terrible as what I thought it was gonna be...' While participants described that adjusting to taking care of the LVAD within the privacy of one's home was easy, venturing out in public with the LVAD was a different experience for the majority of them.

\section{Theme 2: A desire to be normal in public}

In theme 2, Desire for normalcy in public, participants collectively described the experience of being seen in public with the LVAD. It seemed that they had a heightened awareness of the public eye as they continued to build a social life for themselves. For example, participants' responses unanimously described the curious nature of some individuals in public, as richly described by one participant: '...but if you're out in public... and they [people] see this [LVAD]...they'll look at it....and if you catch 'em lookin at it (participant looking up and away)... they will look another way.' Participants were also aware that being seen with the LVAD in public has drawn attention to them, so they were mindful to conceal the outer components of the LVAD to prevent unnecessary public scrutiny, as described by a male participant: 'I sometimes will wear a different type of jacket so I don't upset people too much, you know, 'cause it [LVAD]...you know... [people] get shocked when they see someone with wires stickin out all over [them] ...' As participants reflected upon their new lives with the LVAD, it appeared that they accepted their new self-image as living with this life-sustaining device. Despite participants' awareness of ongoing public scrutiny, it was apparent that they unanimously accepted the inherent curious nature of the public eye and continued to engage in activities of daily living, including recreational activities, and continued to flourish in both personal and social relationships.

\section{Discussion}

This study aimed to explore how patients with LVADs met the HDSCR of modifying self-concept and self-image required to accept this form of treatment and what was needed to restore normalcy. The themes identified were consistent with the reformulated LVAD-specific HDSCR of self-concept and self-image within the theory of self-care (Orem 2001). Although Orem (2001) didn't delineate specific definitions of self-concept and self-image, the distinction between the two phrases became clear through the finalisation of themes.

Theme 1, Having an LVAD means living, reflected the first component of the reformulated LVAD-specific HDSCR, modify self-concept. Although the literature suggested that recipients of LVADs may encounter difficulty modifying their self-concept and therefore unable to achieve a level of self-acceptance to continue with prescribed medical regimen (Chapman et al. 2007, Casida et al. 2011), the participants in our study did not appear to have difficulty with modifying self-concept. Participants unanimously indicated that the LVAD not only improved their QoL, but also saved their life. In fact, they accepted themselves as needing the LVAD to live and therefore readily engaged in the prescribed medical regimen. Participant responses describing this phenomenon included 'appreciation of new technology' and a 'new lease on life'. However, in a related study exploring the impact of LVADs on recipients' bodies and lives (Chapman et al. 2007), retrospective reflections of living with an LVAD after participants received a heart transplant were dramatically difference. They described a profound alteration in body-image elucidated by initial shock and bodily scarring. As the participants in our study never received a donor heart, it is likely that they modified their self-concept to accept the LVAD because they knew that this was the last treatment option for them, or because they were older (e.g. $\geq 65$ ), or knew that there was a shortage of organ donors and they would not likely receive a transplant.

Theme 2, A desire to be normal in public, reflected the second component of the reformulated LVAD-specific HDSCR, modify self-image. In this theme, participants described that self-image was more difficult to manage in public situations. For example, participants were aware that being seen with the LVAD in public had drawn attention to them, so they were mindful to conceal the outer components of the LVAD to prevent unnecessary public scrutiny. Although they acknowledged that it is human nature to be curious, they still wore different types of clothing, or apparel to accommodate the external components of the LVAD to appear 'normal' in public. These behaviours validated the general sets of actions for meeting the reformulated LVAD-specific HDSCR of modify self-image, by taking action to 'preserve ego integrity and psycho-social-sexual relationships while living with an LVAD' (Casida et al. 2009, p. 287). 


\section{Limitations}

This study begins to address the paucity of knowledge related to self-concept and self-image fundamental to the maintenance of health, well-being and QoL of patients living with long-term implantable LVADs. Although our participants provided rich descriptions of their experiences, the sample was comprised mainly of Caucasian men recruited from a single site, limiting generalisability to other LVAD recipients. In addition, the participants in our study did not specifically describe self-care actions geared towards 'developing and maintaining a realistic self-concept' (Orem 2001). As a result, the self-care actions used by participants to modify self-concept and self-image require further investigation.

\section{Conclusion}

This study illustrates a preliminary view into the inside perspective of the phenomenon of modifying self-concept and self-image among patients with implantable LVADS. Participants accepted the LVAD as necessary for them to live and so were able to modify their self-concept. Yet, attaining a sense of normalcy was more difficult in public settings and required additional lifestyle modifications. However, more research is needed to validate the findings and address the study limitations. For example, research using larger sample sizes and diverse populations are needed to examine the self-care actions used to modify self-concept and self-image. Eventually, mixed methods and longitudinal studies can be used to explain self-care actions used by LVAD recipients to modify self-concept. Other components of the theory of self-care (e.g. basic conditioning factors) can be used to identify which socio-demographic variables, such as age, gender and sociocultural aspects, are predictive of an LVAD recipient's ability to engage in self-care actions necessary to modify self-concept.

\section{Relevance to practice}

Study findings advance self-care knowledge in LVAD patient management and can heighten nurses' awareness about selfconcept and self-image as vital components for maintenance of health and well-being among recipients of LVADs. As the utilisation of LVADs is on the rise (Krishnamani et al. 2010), future empirical studies are warranted to guide interventions and evidence-based guidelines aimed at developing clinical practice protocols tailored to improving the QoL of patients with LVADs.

\section{Acknowledgements}

We wish to acknowledge Dr Francis Pagani, MD, PhD and Sarah Fox, BS for their assistance in this study.

\section{Contributions}

Study design: JC, RMP; data collection and analysis: LM, JC, RMP and manuscript preparation: LM, JC, RMP.

\section{References}

American Heart Association (2010) Heart Transplant Statistics. AHA, Dallas, TX. Available at: http://www. americanheart.org/downloadable/heart/ 1265665152970DS3241\%20HeartStroke Update_2010.pdf (accessed 1 February 2010).

Casida JM, Peters RM \& Magnan MA (2009) Self-care demands of persons living with an implantable leftventricular assist device. Research and Theory for Nursing Practice: An International Journal 23, 279-293.

Casida J, Marcuccilli L \& Peters RM (2011) Lifestyle adjustments of adults with long-term implantable left ventricular assist devices: a phenomenological inquiry. Heart and Lung 40, 511-520.

Chapman E, Parameshwar J, Jenkins D, Large S \& Tsui S (2007) Psychosocial issues for patients with ventricular assist devices: a qualitative pilot study. American Journal of Critical Care 16, 72-81.

Grady KL, Meyer P, Mattea A, White-Williams C, Ormaza S, Kaan A, Todd B, Chillcott S, Dressler D, Fu A, Piccione W Jr \& Costanzo MR (2001) Improvement in quality of life outcomes 2 weeks after left ventricular assist device implantation. The Journal of Heart and Lung Transplantation 20, 657-669.

Grady KL, Meyer P, Mattea A, Dressler D, Ormaza S \& White-Williams C (2002) Predictors of quality of life at 1 month after implantation of a left ventricular assist device. American Journal of Critical Care 11, 345-352.

Grady KL, Meyer PM, Mattea A, Dressler D, Ormaza S, White-Williams C,
Chillcott S, Kaan A, Loo A, Todd B, Klemme A, Piccione W \& Costanzo MR (2003) Change in quality of life from before to after discharge following left ventricular assist device implantation. The Journal of Heart and Lung Transplantation 22, 1254-1267.

Grady KL, Meyer PM, Dressler D, Mattea A, Chillcott S, Loo A, White-Williams C, Todd B, Ormaza S, Kaan A, Costanzo MR \& Piccione W (2004) Longitudinal change in quality of life and impact on survival after left ventricular assist device implantation. Annals of Thoracic Surgery 77, 1321-1327.

Hunt SA, Abraham WT, Chin MH, Feldman AM, Francis GS, Ganiats TG, Jessup M, Konstam MA, Mancini DM, Michl K, Oates JA, Rahko PS, Silver MA, Stevenson LW \& Yancy CW 
(2005) ACC/AHA 2005 Guideline Update for the Diagnosis and Management of Chronic Heart Failure in the Adult: A Report of the American College of Cardiology/American Heart Association Task Force on Practice Guidelines (Writing Committee to Update the 2001 Guidelines for the Evaluation and Management of Heart Failure): Developed in Collaboration with the American College of Chest Physicians and the International Society for Heart and Lung Transplantation: Endorsed by the Heart Rhythm Society. Available at: http://www.acc. org/clinical/guidelines/failure//index.pdf. Krishnamani R, DeNofrio D \& Konstam MA (2010) Emerging ventricular assist devices for long-term cardiac support. Nature Reviews Cardiology 7, 71-76.
Lincoln YS \& Guba EG (1985) Naturalistic Inquiry. Sage, Newbury Park, CA.

van Manen M (1990) Researching Lived Experience: Human Science for an Action Sensitive Pedagogy. Suny Press, Albany, NY.

Orem DE (2001) Nursing Concepts of Practice, 6th edn. Mosby, St Louis, MO.

The Journal of Clinical Nursing (JCN) is an international, peer reviewed journal that aims to promote a high standard of clinically related scholarship which supports the practice and discipline of nursing.

For further information and full author guidelines, please visit JCN on the Wiley Online Library website: http:// wileyonlinelibrary.com/journal/jocn

\section{Reasons to submit your paper to JCN:}

High-impact forum: one of the world's most cited nursing journals, with an impact factor of 1.118 - ranked 30/95 (Nursing (Social Science)) and 34/97 Nursing (Science) in the 2011 Journal Citation Reports ${ }^{\circledR}$ (Thomson Reuters, 2011). One of the most read nursing journals in the world: over 1.9 million full text accesses in 2011 and accessible in over 8000 libraries worldwide (including over 3500 in developing countries with free or low cost access).

Early View: fully citable online publication ahead of inclusion in an issue.

Fast and easy online submission: online submission at http://mc.manuscriptcentral.com/jcnur.

Positive publishing experience: rapid double-blind peer review with constructive feedback.

Online Open: the option to make your article freely and openly accessible to non-subscribers upon publication in Wiley Online Library, as well as the option to deposit the article in your preferred archive. 